\title{
Reconstructing the Holocene Variability of the Strength and Radiogenic Isotope Composition of Labrador Sea Water
}

\author{
ALEXANDRA FILIPPOVA ${ }^{1}$, ANNA J. PIEŃKOWSKI ${ }^{2}$, ED \\ HATHORNE $^{3}$ AND MARTIN FRANK $^{4}$ \\ ${ }^{1}$ GEOMAR Helmholtz Centre for Ocean Science Kiel \\ ${ }^{2}$ The University Center in Svalbard (UNIS) \\ ${ }^{3}$ GEOMAR Helmholtz Centre for Ocean Research \\ ${ }^{4}$ GEOMAR Helmholtz Centre for Ocean Research Kiel \\ Presenting Author: afilippova@geomar.de
}

Accurate reconstruction of the Atlantic Meridional Overturning Circulation (AMOC) is not possible without clear constraints on the end-member water mass signatures contributing to North Atlantic deep Water (NADW). Labrador Sea water (LSW) is one of the main components of NADW and plays a crucial role in setting the physical and chemical properties of NADW. Although studies have shown that the $\mathrm{Nd}$ radiogenic signatures of LSW have changed through the Late Quaternary, the role of the water masses contributing to the LSW itself in the formation region has yet to be accessed. Here we present $\mathrm{Nd}$ isotope compositions and rare earth element (REE) patterns of uncleaned foraminifera from 4 marine sediment cores directly at the LSW formation sites (Lancaster Sound, Nares Strait, Hudson Bay, off the coast of Nova Scotia).

The high abundance of benthic foraminifera at Lancaster Sound and Nares Strait locations allowed the direct comparison of $\mathrm{Nd}$ isotopes and REE patterns of benthic and planktonic foraminifera, the latter being generally more porous and able to harbour REE rich overgrowths. However, no difference was observed in their $\varepsilon_{\mathrm{Nd}}$ signatures. Comparison of the REE patterns of benthic and planktonic foraminifera may shed light on the role of benthic sediment flux and pore water exchange in the alteration of the ambient bottom water signatures recorded by foraminifera.

The $\varepsilon_{\mathrm{Nd}}$ signatures from Nares Strait show a $6 \varepsilon_{\mathrm{Nd}}$ unit change towards more radiogenic values at the end of the Early Holocene (from -21.5 to -15.5) following the opening of the Nares Strait. Further analysis of the $\varepsilon_{\mathrm{Nd}}$ signatures of foraminifera from the key locations of main water inflows into the Labrador Sea will better constrain the signatures of the end-member water masses contributing to LSW and their potential variability in the past and aid the reconstruction of the AMOC further downstream. 